ARTICULO

Revista Derecho - Año 2 edición 3: 181 - 194

Web: http://www.revistaderecho.pe E-mail: editorial@revistaderecho.pe

ISSN 2313-6944

\title{
DERECHO CONSUETUDINARIO: LEY DE LA FUNCIÓN JURISDICCIONAL Y SU COORDINACIÓN CON LA JURISDICCIÓN ORDINARIA DE LAS COMUNIDADES CAMPESINA Y NATIVA
}

\author{
Grover Luis Mamani Flores \\ Rene Meliton Arapa Condori*
}

INFORMACIÓN DEL ARTICULO

Art. Recibido: 25/01/16

Art. Aceptado: 03/06/16

Art. Publicado: 18/12/18

PALABRAS CLAVE:

Convenios internacionales

Comunidad campesina y nativa

Derecho consuetudinario

Función jurisdiccional

Justicia Comunitaria

Pueblos indígenas u originarios

Pluralismo jurídico

\section{RESUMEN}

En el Perú, el derecho consuetudinario de los pueblos indígenas $\mathrm{u}$ originarios, comunidades campesinas y nativas en particular el derecho a disfrutar de sus propias leyes, están reconocidos en la Constitución Política de 1993 y en los tratados internacionales firmados por el país. La Constitución ratifica la coexistencia de la jurisdicción especial comunal y la jurisdicción ordinaria y establece su coordinación, sin embargo, no existe una normatividad complementaria que pueda desarrollar el artículo 149 de la Constitución Política. En consecuencia, el objetivo principal del ensayo es determinar y sistematizar el derecho consuetudinario en una ley que pueda desarrollar y establecer mecanismos de coordinación. Como resultado del análisis se propone la ley que desarrollará el artículo 149 de la Constitución Política Del Perú, iniciativa que busca contribuir al proceso de diálogo y coordinación entre la función jurisdiccional de las autoridades comunales de los pueblos indígenas u originarios y las autoridades de la jurisdicción ordinaria.

CUSTOMARY LAW: LAW OF JURISDICTIONAL FUNCTION AND ITS COORDINATION WITH THE ORDINARY JURISDICTION IN PEASANT AND NATIVE COMMUNITIES

ARTICLE INFO

Article Received: 25/01/16

Article Accepted: 03/06/16

Article Published: 18/12/18

\section{ABSTRACT}

In Peru, the customary law of indigenous people, peasant and native communities in particular the right to use their own laws is recognized in the Political Constitution of 1993 and in the international treaties signed by the country. The Con-

Bachilleres de la Facultad de Ciencias Jurídicas y Políticas, Escuela Profesional de Derecho de la Universidad Nacional del Altiplano. 
KEY WORDS:

International Conventions

Peasant and native community Customary law Jurisdictional function Community justice Indigenous people Legal pluralism. stitution confirms the coexistence of the special communal jurisdiction and the ordinary jurisdiction and establishes its coordination; however, there is not a complementary body of norm that can develop the article 149 of the Political Constitution. Therefore, the main objective of this paper is to determine and systematize the customary law in a law that can develop and establish coordination mechanisms. As a result of the analysis there is a proposed law that will develop the article 149 of the Political Constitution of Peru, an initiative that seeks to contribute to the process of dialog and coordination between the jurisdictional function of the communal authorities of indigenous people and the authorities of the ordinary jurisdiction. 


\section{INTRODUCCIÓN}

En los países andinos existen importantes mecanismos y sistemas de justicia local, como la justicia comunitaria o indígena y la justicia de paz, las cuales, desde diversas perspectivas, permiten a la población de zonas rurales y urbanas marginales concretar derechos y resolver conflictos cruciales de su vida cotidiana. Se constituyen, así, en vías importantes para el acceso a la justicia y en ámbitos de intensa experiencia intercultural en la administración de justicia.

En la actualidad, tenemos un sistema de justicia etnocéntrica que no es coherente con nuestra realidad pluricultural. aún, en la sociedad peruana están vigentes formas de marginación $\mathrm{y}$ tensiones internas que se expresan en el derecho y que han derivado en que comunidades campesinas y nativas sean discriminadas y explotadas a lo largo de la historia, todo este proceso siguiendo a hurtado pozo, es agravado por un Estado centralista, mono cultural y con una visión occidental, que desconoce olímpicamente las concepciones jurídicas consagradas en los pueblos indígenas u originarios, comunidades campesinas y nativas, ni siquiera se preocupa por garantizar y organizar la infraestructura mínima para su aplicación. Por el contrario, destruye y estigmatiza el patrimonio cultural de estos pueblos, en la misma perspectiva, se debe considerar que las normas que rigen a los hombres (ja'ques y runas) también rigen en su relación con la naturaleza (ética cósmica).
Así quedando sin efecto práctico, el artículo $149^{\circ}$, el inciso 19 del artículo 2 de la carta magna que constituyen avances legales muy importantes con relación a la situación descrita, reconoce la atribución de ejercer funciones jurisdiccionales a las autoridades de las comunidades campesinas y nativas, con el apoyo de las rondas campesinas. Esto significa que mediante esta norma constitucional se ha estableciendo una jurisdicción especial. Por lo tanto, como jurisdicción especial, sus decisiones deben tener carácter de cosa juzgada y no pueden ser revisados por ninguna de las otras jurisdicciones, salvo cuando afecten derechos humanos, en cuyo caso, le corresponderá al tribunal constitucional pronunciarse al respecto.

En efecto, llama la atención que mientras los países vecinos como Ecuador, Bolivia y Venezuela siguiendo el modelo colombiano y peruano, reconozcan la justicia especial indígena en sus Constituciones Políticas Nacionales, en nuestro país parece que es un destino se quiere retroceder, dando la espalda no sólo a este proceso latinoamericano, sino lo que es peor, a una realidad arraigada a lo largo del territorio nacional.

Se pretende proponer una ley para el mayor reconocimiento del pluralismo jurídico y la promoción del acceso a la justicia de las poblaciones o nacionalidades originarias de nuestro país. Por ello, se tiene como objetivo del ensayo analizar, identificar y diseñar los contenidos, principios y procedimientos del derecho consuetu- 
dinario que debe ser sistematizado en la ley de la función jurisdiccional de las comunidades campesina y nativa, como tambien, determinar el nivel de coordinación y cooperacion con la jurisdicción ordinaria.

\section{DESARROLLO TEÓRICO}

\section{La Jurisdicción Ordinaria y sus problemas}

La función jurisdiccional reconocida a las comunidades campesinas y nativas en el artículo 149 de la Constitución Política, es aquella ejercida por las comunidades campesinas o nativas indígenas en tanto grupo humano preexistente a la formación del Estado con características propias que las diferencian de la población en general.

De esta manera, el Estado Peruano reconoce, en relación con los pueblos indígenas, el respeto a la diversidad y el pluralismo cultural, lo que tendrá que efectuarse siempre dentro del marco de respeto a los derechos fundamentales, el dialogo intercultural, los principios constitucionales y los valores superiores que la constitución incorpora, tales como la dignidad de la persona, los principios de soberanía del pueblo, el Estado democrático de derecho y la forma republicana de gobierno actual.

En consecuencia, se debe reafirmar que sólo las comunidades campesinas y nativas, que tienen la calidad de indígenas conforme a las normas de derecho interno e internacional, tienen la facultad de ejercer función jurisdiccional de acuerdo con su derecho consuetudinario y con respeto de los derechos fundamentales.

Todo este proceso siguiendo a hurtado pozo es agravado por un Estado centralista, monocultural y con una visión occidental, que desconoce olímpicamente las concepciones jurídicas consagradas en los pueblos originarios, comunidades campesinas y nativas, ni siquiera se preocupa por garantizar y organizar la infraestructura mínima para su aplicación, Por el contrario, destruye y estigmatiza el patrimonio cultural de estos pueblos.

De esta manera, tenemos un sistema de justicia etnocéntrica que no es coherente con nuestra realidad pluricultural. Aún, en la sociedad peruana están vigentes formas de marginación y tensiones internas que se expresan en el derecho y que han derivado en que comunidades andinas y nativas sean discriminadas $y$, muchas veces, explotadas, a lo largo de la historia. Frente a ello, el artículo 149 de la Constitución, al reconocer el derecho de las comunidades a aplicar su derecho consuetudinario; y el inciso 19 del artículo 2 de la carta magna constituyen avances legales muy importantes con relación a la situación descrita. Sin embargo, no sirve mucho si no se materializada a través de una norma de desarrollo constitucional.

Por otro lado, es pertinente establecer que la cosmovisión andina es diferente a la cosmovisión occidental, tiene una lógica distinta y se expresa en infinidad de maneras: la idea andina del trabajo como una fiesta y no como 
un castigo. El sentido del espacio y del tiempo se reduce en una solo palabra "pacha" y no son elementos separados como en la lógica accidental. La vinculación espiritual y casi existencial del originario con la tierra. El aprecio a la autoridad de los abuelos. La idea misma de la administración de justicia. "en la misma perspectiva, se debe considerar que las normas que rigen a los hombres (ja'ques y runas) también rigen en su relación con la naturaleza (ética cósmica); por ello, cuando se falta a los padres, se está atentando contra el orden natural $y$, consecuentemente, el castigo de la naturaleza afecta a toda la comunidad” (García 2009: p. 237). En esta perspectiva, "el adulterio se castiga no solo porque compromete a la sociedad sino a toda la naturaleza; por eso, se chicotea al adúltero no solo para restablecer el equilibrio social sino también cósmico" (Rubio, 1988: p. 289).

Asimismo, la concepción de Estado que tienen los pueblos originarios y comunidades campesinas no es igual a la concepción de Estado de origen occidental europeo. Para ellos, no es necesaria la división de poderes, es absurdo e innecesaria, por eso es, la asamblea la que legisla, estableciendo la aplicación de normas mediante acuerdos, juzga, la conducta delictiva o infractora que afecta no solo al individuo sino al orden de la comunidad y al equilibrio cósmico (todos los miembros participan en el juzgamiento), y ejecuta los acuerdos.

Asimismo, los pueblos originarios, comunidades campesinas y nati- vas, han sido flagelados culturalmente por el derecho occidental sufriendo un atentando contra el sentido de la reciprocidad y la comunidad (comunitarismo-ayllu). Por lo tanto, no es cierto que los grupos indígenas vivan en anarquía sin ley, sin justicia, viviendo y muriendo a su capricho, tienen ley, tienen justicia, solo que sus leyes y sus costumbres son distintas a las nuestras.

\section{La Jurisdicción Originaria Campe- sina y Nativa y su Regulación Nor- mativa.}

"El artículo 1490 de la Constitución Política reconoce la atribución de ejercer funciones jurisdiccionales a las autoridades de las comunidades campesinas y nativas, con el apoyo de las rondas campesinas. Esto significa que mediante esta norma constitucional se ha estableciendo una jurisdicción especial. Por lo tanto, como jurisdicción especial, sus decisiones deben tener carácter de cosa juzgada y no pueden ser revisados por ninguna de las otras jurisdicciones". (Yrigoyen, 1995: p. 39-40.), salvo cuando afecten derechos humanos, en cuyo caso, le corresponderá al tribunal constitucional pronunciarse al respecto.

\section{Características del derecho consue- tudinario de los Pueblos Indígenas u Originarios Comunidades Cam- pesinas y Nativas del Perú.}

El derecho indígena se sustenta en algunos principios fundamentales que se originan en dos instancia o ambientes diferentes: el tiempo y el espacio, pero que con el pasar del tiempo 
se han transformado en la razón de estar el derecho indígena dentro de lo que hoy política y jurídicamente se constituyen pueblos y nacionalidades indígenas. a pesar de los cambios sufridos en la institucionalidad y las normas de los pueblos indígenas u originarios, debido a las transformaciones sociales y las relaciones de producción perviven y están en vigencia instituciones sociales, culturales, políticas, económicas y jurídicas, unas más desarrolladas que otras instituciones desarrolladas en función de la lógica indígena, del pensamiento y su concepción del mundo: sus principios, normas y valores.

Los principios filosóficos de complementariedad, reciprocidad y colectividad, son los sustentos fundamentales en la elaboración de la normativa, el ordenamiento social y el surgimiento del derecho indígena. Concomitante a los principios de solidaridad, reciprocidad y colectividad se encuentran implícitas, especialmente en los pueblos indígenas u originarios, la trilogía normativa de la conducta de los pueblos indígenas que ha posibilitado el control social y el ejercicio de la administración de justicia, ellos son el ama killa (no ser holgazán o perezoso), ama llulla (no mentir), ama shua (no robar).

Estos principios han sido acogido por la organización de las naciones unidas (onu) que aprobó por unanimidad los principios ancestrales andinos ama sua (no seas ladrón), ama llulla (no seas mentiroso) y ama qhella (no seas flojo) como una norma mun- dial para una gestión pública más eficiente.

Como un claro ejemplo de la evolución de la normativa indígena, podemos apreciar que históricamente dentro del estado inca debían observar estos preceptos legales. Además, esta trilogía normativa, estaba íntimamente vinculada a las distintas legislaciones que en ese entonces existían, como la legislación penal, laboral, agraria.

Pero ¿̇será posible normar el desenvolvimiento de una colectividad humana con tan solo una trilogía? la respuesta es afirmativa. En las comunidades indígenas, tanto para los hombres como para las mujeres de todas las edades, más que una norma de conducta es una norma legal que le reviste de respeto a la persona y le da un status integral. de respeto.

El llulla, pierde autoridad y pier-

q'ella, se refiere la inactividad a la quietud y a la falta de iniciativas dentro de la familia y de la comunidad; esto se traduce en "pereza".

Una persona con estas características en la comunidad sería considerada como una lacra de la sociedad y de la familia, un antisocial; para los indígenas, no cabe la inactividad, porque acarrearía problemas sociales y familiares; por ejemplo, no levantarse temprano es sinónimo de enfermedad. Según las tradiciones, de los abuelos y padres el levantarse temprano e iniciar actividades es sinónimo de salud. 
El sua, es considerado como aspecto más grave y quizá la suma y la consecuencia de la inobservancia de las dos normas anteriores. Un miembro de la sociedad convertido en sua (ladrón), no sólo altera la convivencia pacífica de la colectividad, sino que afecta la estructura orgánica de la misma. El individuo o la colectividad sorprendido en el cometimiento de este acto, es procesado severamente sancionado, pero sin poner en riesgo el criterio de que las sanciones deben encaminarse a mantener el equilibrio en la comunidad y en la sociedad; para los indígenas, el trabajo es un hecho natural inherente a todas las personas por lo tanto no hay razón para apropiarse de lo ajeno.

En el Estado Incásico, al ladrón se le castigaba severamente, y la reincidencia se sancionaba hasta con la pena capital; ya que, según cuenta el cronista Garcilaso de la Vega (1961), en tiempo de los incas, el ladrón era considerado como un enviciado (poseedor de un demonio) y no una persona que roba por necesidad o codicia.

El no ser perezoso o holgazán se vinculaba estrechamente con las cuestiones de trabajo. El buen trabajador podía llegar a ser jefe de los señoríos étnicos. En cambio, el vago estaba considerado como un vulgar delincuente o antisocial.

En cuanto a la norma legal ama llulla (no ser mentiroso), en tiempos de los incas la mentira era considerada como un delito grave; y para que sus subordinados no mientan, el inca y los dignatarios daban ejemplos; al que incu- rría en la materia, se lo castigaba con la azotada, y se lo consideraba poseedor de una energía negativa, que en el mundo indígena se conoce como el chiki.

$\mathrm{Al}$ poseedor de este mal, se lo sometía a consideración de yatiri (médico indígena), a fin de que él les expulse esta energía negativa; y si con esto no se curaba y seguía mintiendo, era condenado a la pena de castigo público, y en último de los casos con la pena de muerte. El castigo era severo, así este delito no existía o era muy poco común.

En la actualidad, dentro del mundo indígena, al mentiroso no sólo se lo considera trasgresor de las normas legales (la trilogía establecida), sino que también se lo considera como una persona poseída de energía negativa chiki. Por lo tanto, no cabe una sanción punitiva que sería injusta, si la persona poseída de este mal no es curada con anterioridad al establecimiento de una pena.

De esta manera, la trilogía establecida constituye el fundamento, la base, la razón de ser del derecho indígena o sistema jurídico propio, ya que, en una comunidad normada por estos tres ejes principales, no cabe la protesta y el descontento, y no es concebible la transgresión de las normas que regulan la vida comunitaria: está prohibido robar, ser vago y mentir.

A las normas y procedimientos propios de los pueblos indígenas, se ha tildado como ajusticiamientos linchamientos o justicia por mano propia, estas no son las características de los 
usos y costumbres y del derecho consuetudinario de los pueblos indígenas, más bien estos hechos descalifican al derecho indígena, no es lo mismo justicia indígena que ajusticiamiento o linchamiento.

En la justicia indígena requiere de un proceso previo de comprobación de responsabilidad antes de imponer cualquier sanción. No constituye una forma popular de administrar justicia aplicando la pena capital. Por el contrario, es un conjunto articulado de normas y procedimientos que derivan en juzgamiento basado en evidencias y en una sentencia basada en la valoración de la prueba aportada, de ahí que, de ninguna manera puede equipararse hechos aislados como los ajusticiamientos con el sistema de justicia indígena.

Hay que reconocer que puede darse el caso que las autoridades indígenas se excedan en la imposición de una sanción, pero no por eso se va a negar de por sí la aplicación de procedimientos tradicionales que en la gran mayoría de los casos sólo tiene efectos simbólicos o curativos.

El derecho y la justicia indígena están facultados para regular y resolver situaciones y conflictos en todo tipo de materias, sin importar su gravedad o cuantía.

Durante la última década se ha promovido el reconocimiento de los derechos colectivos de los pueblos indígenas. El punto de partida tuvo lugar con el reconocimiento del carácter pluricultural y pluriétnico de los
Estados y sus sociedades, hecho que trastocó los paradigmas del Estado monoétnico y homogénico definido en la supremacía de la cultura occidental dominante.

Pero los avances posteriores en el ordenamiento constitucional o en el ámbito de las normas internacionales como el Convenio 169 de la OIT, nos ubica frente a un proceso histórico, si consideramos que sus reivindicaciones en materia de reconocimiento de derechos, son anteriores a la creación de los mismos estados.

Por ello los pueblos indígenas al no haber sido partícipe en la fundación de los Estados se mantuvieron ajenos a su funcionamiento político y jurídico, sin dejar de reclamar el reconocimiento de sus derechos específicos fundados en la continuidad histórica de sus pueblos.

\section{Derechos Colectivos de los Pueblos Indígena u Originaria}

De acuerdo al Convenio 169 y la legislación peruana, son derechos colectivos de los pueblos indígenas, la que pertenece a un conjunto de individuos caracterizado por pertenecer a un pueblo indígena $\mathrm{u}$ originario o grupo social.

Los derechos colectivos de los pueblos indígenas reconocidos por la Constitución Política del Perú, el Convenio 169, entre otros tratados internacionales incluyen:
1) Derecho a la identidad cultural.
2) Derecho a la participación de los pueblos indígenas. 
3) Derecho a la consulta.

4) Derecho a elegir sus prioridades de desarrollo.

5) Derecho a conservar sus costumbres, siempre que éstas no sean incompatibles con los derechos fundamentales reconocidos internacionalmente.

6) Derecho a la jurisdicción especial.

7) Derecho a la tierra y el territorio, es decir al uso de los recursos naturales que se encuentran en su ámbito geográfico y que utilizan tradicionalmente de la legislación vigente;

8) Derecho a la salud con enfoque intercultural.

9) Derecho a la educación intercultural,

10) Derecho a la libre determinación, entre otros (artículo 3 de la Ley 29785).

Criterios de Identificación de las Comunidades Campesinas o Nativas Como Indígenas.

Existen criterios que permiten su identificación. Así, en aplicación del artículo 7 de la Ley 29785, Ley del derecho a la consulta previa a los pueblos indígenas u originarios, reconocido en el Convenio 169 de la Organización Internacional del Trabajo, para identificar a los pueblos indígenas u originarios se toman en cuenta criterios objetivos y subjetivos; a saber:

\section{A) Criterios objetivos:}

a) Descendencia directa de las poblaciones originarias del territorio nacional. b) Estilos de vida y vínculos espirituales e históricos con el territorio que tradicionalmente usan $\mathrm{u}$ ocupan.

c) Instituciones sociales y costumbres propias.

d) Patrones culturales y modo de vida distintos a los de otros sectores de la población nacional.

B) Criterio subjetivo; se encuentra relacionado con la conciencia del grupo colectivo de poseer una identidad e ideología indígena u originaria”.

En concordancia, el artículo 1 del Convenio OIT 169 sobre pueblos indígenas y tribales en países independientes establece los mismos criterios de determinación de pueblos indígenas.

En ese entender, la justicia originaria campesina y nativa se constituye en una excepción al principio de unidad y exclusividad de la jurisdicción por parte del poder judicial. Así lo reconoce la doctrina, cuando señalan que el artículo $149^{\circ}$ de la constitución "permite el ejercicio de la función jurisdiccional por un órgano u organización judicial distintos al poder judicial, limitándose el principio de unidad y exclusividad del poder judicial para dicha función consagrado en el art. 139, inciso 1". El principio de unidad y exclusividad no es absoluto, tiene excepciones (siles a. y otros 2003: p 23).

Como son la justicia constitucional a cargo del tribunal constitucional, la justicia electoral a cargo del jurado nacional de elecciones, la justicia militar a cargo de los militares estos den- 
tro del sistema normativo ordinaria y la justicia comunal es de jurisdicción especial a cargo de las comunidades campesinas y nativas.

De otra parte, es preciso señalar que la "Constitucionalización" de la jurisdicción originaria o comunal reviste a ésta de una especial importancia. En efecto, incorporar a la constitución un precepto referido a la jurisdicción especial comunal, significa conceder a ésta, de una protección jurídica, pues la considera una forma de organización básica, parte constitutiva del pacto político fundante del Estado.

En ese sentido, también se tiene el convenio 169 de la organización internacional del trabajo que forma parte de nuestro ordenamiento jurídico, y es obligatorio su cumplimiento por todas las entidades estatales. Además, estos "tratados internacionales sobre derechos humanos (...) detentan rango constitucional" (Sentencia del Tribunal Constitucional No 000252005-PI/TC y 0026-2005-PI/TC, Fj. 26). en ese sentido, en aplicación del Artículo V del título preliminar del código procesal constitucional, los tratados sobre derechos humanos en general, y el convenio 169 de la OIT en particular, tienen la función de complementar normativa e interpretativamente las disposiciones constitucionales sobre pueblos indígenas y, en particular, las referidas a sus derechos fundamentales y las garantías institucionales con las que tengan relación, en cuyo marco debemos de interpretar las normas referidas a la justicia comunal. En esa perspectiva, tenemos el numeral 2 del artículo 8, que debe ser interpretada en concordancia con el numeral 1 del artículo 9 .

De otro lado, se tiene la declaración de derechos de los pueblos indígenas. Este instrumento del derecho internacional de los derechos humanos conlleva una fuerza moral, además de una evidente orientación de la comunidad internacional en materia de garantía y respeto de los pueblos indígenas, al anidar en su contenido aquellas metas y objetivos que la comunidad internacional se impone.

Bajo estos parámetros normativos e interpretativos es que se debe entender y desarrollar la justicia originaria campesina y nativa.

\section{Alcance de la Jurisdicción Especial Comunal.}

La aplicación el artículo $149^{\circ}$ de la Constitución, si es de aplicación el denominado fuero especial comunal, en tanto en cuanto el reconocimiento de una jurisdicción especial constituye un límite objetivo a la jurisdicción ordinaria Desde dicha norma constitucional es posible, identificar los siguientes elementos que comporta la jurisdicción especial comunal.

A. Elemento Humano. Existencia de un grupo diferenciable por su origen étnico o cultural y por la persistencia diferenciada de su identidad cultural. Como ha quedado expuesto en los párrafos anteriores, las comunidades campesinas y nativas tienen este atributo socio cultural.

B. Elemento Orgánico. Existencia de autoridades tradicionales 
que ejerzan una función de control social en sus comunidades. Las comunidades campesinas y nativas, precisamente, es esa organización comunal que, entre otras múltiples funciones, asume funciones jurisdiccionales para la solución de los conflictos. Ellas cuentan con la necesaria organización, con el reconocimiento comunitario y con capacidad de control social.

C. Elemento Normativo. Existencia de un sistema jurídico propio, de un derecho consuetudinario que comprenda normas tradicionales tanto materiales cuanto procesales y que serán aplicadas por las autoridades de las comunidades campesinas y nativas. Esas normas, en todo caso y como perspectiva central de su aceptabilidad jurídica, han de tener como fundamento y límite la protección de la cultura comunitaria, asegurar su mantenimiento y prevenir las amenazas a su supervivencia.

D. Elemento Geográfico. Las funciones jurisdiccionales, que determinan la aplicación de la norma tradicional, se ejercen dentro del ámbito territorial de la respectiva las comunidades campesinas y nativas. El lugar de comisión del hecho, determinante de la aplicación de la norma tradicional, es esencial para el reconocimiento constitucional de la respectiva función jurisdiccional de la las comunidades campesinas y nativas: las conductas juzgadas han de ocurrir en el territorio de ésta.

E. Elemento Subjetivo. La conciencia de su autodefinición de identidad como indígena u originaria y comunidad campesina o nativa.

A estos elementos se une el denominado factor de congruencia. El derecho consuetudinario que debe aplicar las comunidades campesinas y nativas no puede vulnerar los derechos fundamentales de la persona. Se trata de una condición de legitimidad y límite material para el ejercicio de la función jurisdiccional especial comunal.

\section{Las Rondas Campesinas y las Facul- tades Jurisdiccionales.}

El artículo 149 de nuestra Constitución Política asigna a las rondas campesinas la función de "apoyo" a las autoridades de las comunidades campesinas y nativas, en el ejercicio de facultades jurisdiccionales, negando de alguna manera la realidad arraigada en nuestro país. Pero la ley 27908 (ley de rondas campesinas), recogiendo dicha realidad viva de nuestro país, en su artículo $1^{\circ}$ establece que "Los derechos reconocidos a los pueblos indígenas y comunidades campesinas y nativas se aplican a las rondas campesinas en lo que les corresponda y favorezca". Desarrollando de esta manera la norma constitucional. Esta ley también debe interpretarse de acuerdo al principio pro indígena recogido en el artículo 35 del convenio 169 de la OIT. (Yrigoyen R. 2002: p. 83 y 98) 
Por tal razón, en la iniciativa Legislativa se plantea que la ronda campesina podrá administrar justicia siempre que la asamblea o la máxima autoridad del pueblo originario, comunidad campesina y nativa, así lo acuerde y además debe tener reconocimiento colectivo mediante sus propios mecanismos de legitimidad.

\section{Grupos No Facultados para Ejercer Jurisdicción Especial Indígena.}

El artículo 149 de la Constitución Política del Perú es claro y taxativo al establecer que la jurisdicción especial sólo la pueden ejercer tanto las comunidades campesinas como las comunidades nativas con cosmovisión indígena como expresión del derecho a la identidad cultural.

La exclusión de determinadas comunidades campesinas de la facultad de administrar justicia de conformidad con el artículo 149 de la Constitución Política, se fundamenta en el hecho informado por Wilfredo A: "[...] en otra región predominantemente indígena, como puno, existen comunidades que tienen un carácter más bien formal, puesto que se organizaron intencionalmente para obtener determinados beneficios, cuando se disolvieron las empresas asociativas $y$ las SAIS durante el primer gobierno de Alan García. Estas comunidades campesinas puneñas existen más para el derecho estatal que para la realidad: son más bien una suma de pequeños propietarios y las autoridades comunales tienen un carácter formal, sin injerencia en la administración de justicia”.
La misma situación puede producirse en otros ámbitos geográficos en el que a pesar que un pueblo indígena reconocido como comunidad campesina o nativa, el derecho consuetudinario indígena sólo no es aplicado. El reconocimiento meramente legal de un grupo como comunidad campesina o nativa no puede autorizar el ejercicio de la jurisdicción especial indígena si en la práctica dicho colectivo no expresa su identidad cultural.

En el caso de las rondas campesinas, si bien cumplen un rol importante en la sociedad, los mismos no están facultados por el artículo 149 de la Constitución Política para administrar justicia. La práctica organizada y loable de resolver conflictos en determinado ámbito territorial en ausencia o por inacción de autoridades estatales de seguridad y de administración de justicia, no modifican las disposiciones constitucionales. No obstante, el artículo 1 de la ley 27908, ley de rondas campesinas, delimita claramente sus funciones estableciendo que las rondas campesinas "apoyan el ejercicio de funciones jurisdiccionales de las comunidades campesinas y nativas, colaboran en la solución de conflictos y realizan funciones de conciliación extrajudicial conforme a la constitución y la ley". (Resaltado agregado). En consecuencia, no existe disposición legal ni constitucional que autorice a las rondas campesinas a ejercer jurisdicción especial. En esa misma línea de ideas, el derecho internacional y, especialmente, en el convenio 169 de la organización internacional del trabajo, no reconocen a las rondas 
campesinas tal función de jurisdicción especial. (Ardito, 2004).

\section{CONCLUSIONES}

El derecho consuetudinario en el marco del pluralismo jurídico es reconocido en el año 1993 en el art. 149 de la Constitución Política del Estado y el Convenio 169 de la OIT en los artículos 8 y 9 está vigente en las comunidades campesinas y nativas o pueblos indígenas u originarios y rondas campesinas. Sin embargo, existe problemas de deslinde jurisdiccional, es por ello, la necesidad de una norma de desarrolló del art. 149. La ley de la función jurisdiccional y su coordinación con la jurisdicción ordinaria de las comunidades campesina y nativa, observando los derechos fundamentales de la persona.

La Ley de la función jurisdiccional de las comunidades campesina y nativa en sus contenidos, principios y procedimientos del derecho consuetudinario debe ser sistematizada sin afectar los derechos colectivos de los pueblos y garantiza el derecho a la jurisdicción especial, a sus propias leyes y el derecho a conservar sus instituciones propias, en el marco del convenio 169 de la OIT y los derechos fundamentales de la persona humana.

La Ley de función jurisdiccional de las comunidades campesina y nativa y la jurisdicción ordinaria en el marco del pluralismo jurídico e interculturalidad debe establecer proceso de dialogo, cooperación y coordinación entre la jurisdicción ordinaria y la jurisdicción especial. Las decisiones de las autoridades indígenas emitidas en sus funciones jurisdiccionales, serán respetadas por las instituciones y autoridades públicas y privadas y tendrán la misma validez y fuerza obligatoria que los adoptados por la justicia ordinaria y los órganos de la función judicial. Por consiguiente, no podrán volver a ser juzgados ni revisados por ningún otro órgano. Salvo cuando afecte derechos fundamentales de la persona, a través del tribunal de garantía constitucional; la resolución emitida por la autoridad indígena tendrá valor de cosa juzgada.

La Constitución Política del Perú al referirse puede ejercer funciones jurisdiccionales, no establece una competencia material, no específica que tipo de delitos ni qué tipo de gravedad. No obstante, para los pueblos indígenas y para la justicia indígena, conflicto dentro de su territorio constituye toda acción, acto u omisión que desestabiliza el orden establecido dentro de la colectividad indígena que se encuentra asentado en un territorio definido. De tal manera que todo acto que este considerado por la comunidad, pueblo o nacionalidad indígena como ilícita, como no permitido, será juzgado a través de las autoridades indígenas.

La jurisdicción territorial comprende el espacio físico determinado, la totalidad del hábitat en donde las comunidades, pueblos y nacionalidades indígenas habitan, es el territorio indígena, lugar en donde vivimos y desarrollamos nuestras actividades cotidianas, nuestra cultura, leyes, formas de organización y economía propia, comprende la superficie de la tierra y el subsuelo. 
Los sucesores a los ayllus, las comunidades campesinas y nativas rondas campesinas y parcialidades, los pueblos y las nacionalidades indígenas son colectividades distintas y diferentes del resto de la sociedad peruana, y como tal reúnen dos elementos: material y subjetivo. El primero relacionado con los aspectos externos como la vestimenta, la lengua, los sistemas jurídicos, las costumbres, los ritos, la cosmovisión, formas de organización, sistemas de economía dentro de un determinado territorio y el segundo relacionado con el aspecto psicológico, es decir la convicción del colectivo humano de autodefinición de ser distinto al resto y pertenecer a un grupo diferente

\section{BIBLIOGRAFÍA}

1. ACUERDO PLENARIO No 1-2009/CJ-116; Rondas Campesinas y Derecho Penal, Corte Superior de Justicia del Perú.

2. Ardito, W. (2004); Rondas Campesinas, Consorcio Justicia Viva No 142, en: http://www. justiciaviva.org.pe /justiciamaill jm0142. htm.

3. CERIAJUS (2003); Comisión Especial de Reforma Integral de la Administración de Justicia.

4. Condor, E. (coord.) W. L. (2009); Manual informativo para pueblos indigenas.

5. DEFENSORIA DEL PUEBLO (2006); El Reconocimiento Estatal de las Rondas Campesinas.
6. Gómez, M. (1995); Derechos Indigenas. Lectura comentada del Convenio 169 de la Organización Internacional del Trabajo.

7. Hurtado, J. (2008); Derecho penal y Diferencias Culturales.

8. Korsbaek, L. (2004); El Convenio $N^{\circ} 169$ de la OIT. Entre el derecho, la antropología y la historia.

9. Laos, A., Paredes, P. y Rodríguez, E. (2003); Rondando por Nuestra Ley.

10. ORGANIZACIÓN INTERNACIONAL DEL TRABAJO (2009); Los derechos de los pueblos indigenas y tribales en la práctica.

11. ORIN S. (1989); Senderos inesperados: las rondas campesinas de la sierra sur central.

12. Pajuelo, R. (2000); Imágenes de la comunidad. Indígenas, campesinos y antropólogos en el Perú"

13. Peña, A. (2004); Poder judicial comunal aymara en el sur andino.

14. Rodríguez, César (2007). Las rondas campesinas en el Sur Andino.

15. Rubio, Marcial. (1988); Costumbres y Usos en el Código Civil.

16. Ruiz, J. (2006); Justicia Comunal y Justicia Estatal en el Perú.

17. Yrigoyen, R. (2006); Hitos del Reconocimiento del Pluralismo Jurídico y el Derecho Indigena en las Politicas Indigenas y el Constitucionalismo Andino. 